\title{
A New Method to Analyze the Mine Liquidation Costs in Poland
}

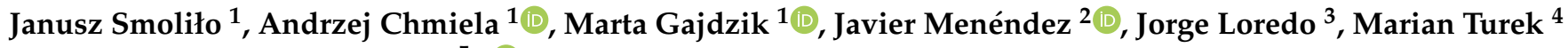 \\ and Antonio Bernardo-Sánchez ${ }^{5, *(\mathbb{D})}$
}

1 Spółka Restrukturyzacji Kopalń S.A., Strzelców Bytomskich 207, 41-914 Bytom, Poland; jsmolilo@srk.com.pl (J.S.); achmiela@srk.com.pl (A.C.); marta.gajdzik@srk.com.pl (M.G.)

2 Mining Department, SADIM Engineering, Avda. Galicia, 44, 33005 Oviedo, Spain; javier.menendez@sadim.es

3 Mining Exploitation Department, University of Oviedo, 33004 Oviedo, Spain; jloredo@uniovi.es

4 Central Mining Institute, Gwarków 1, 40-166 Katowice, Poland; mturek@gig.eu

5 Department of Mining Technology, Topography and Structures, University of León, 24071 León, Spain

* Correspondence: abers@unileon.es

check for

updates

Citation: Smoliło, J.; Chmiela, A.; Gajdzik, M.; Menéndez, J.; Loredo, J.; Turek, M.; Bernardo-Sánchez, A. A New Method to Analyze the Mine Liquidation Costs in Poland. Mining 2021, 1, 351-363. https://doi.org/ $10.3390 /$ mining 1030022

Academic Editors:

Mostafa Benzaazoua and

Mustafa Kumral

Received: 1 October 2021

Accepted: 2 December 2021

Published: 4 December 2021

Publisher's Note: MDPI stays neutral with regard to jurisdictional claims in published maps and institutional affiliations.

Copyright: (c) 2021 by the authors. Licensee MDPI, Basel, Switzerland. This article is an open access article distributed under the terms and conditions of the Creative Commons Attribution (CC BY) license (https:// creativecommons.org/licenses/by/ $4.0 /)$.

\begin{abstract}
Coal mine closure processes are being carried out in the European Union due to the current energy transition. The use of coal-fired power plants has been significantly reduced in recent years. Because of the significant financial outlays, processes of rationalization and minimization of the mine liquidation cost should be carried out. In this paper, a statistical analysis of the liquidation processes in hard coal mines in Poland was carried out. A new tool was developed in order to optimize the mine liquidation costs. The mine liquidation process can be divided into ten different processes, which have been analyzed in detail in this research work. The method of the assessment of the amount of estimated liquidation costs described is based on the analysis of the total liquidation cost. The presented method of signaling deviations of the costs of the liquidation of the mining plant from the average value is a useful tool in the process approach to the issues connected with the restructuring of post-industrial property. The presented cost assessment procedure may facilitate the monitoring of conducted activities in terms of rationalization and minimization of the costs incurred. Finally, the proposed method for assessing the cost of mine liquidation is understandable, simple, and easy to use for applications in preliminary design works and on-going engineering works.
\end{abstract}

Keywords: mine closure; process management; restructuring of mining enterprises; coal mine liquidation

\section{Introduction}

The reduction in greenhouse gas emissions in the European Union by 2050 implies the cutting of electricity production at coal-fired power plants, and therefore the coal mines need to be closed. Grmela et al. [1] analyzed the process of mine liquidation as an environmental, economic, and legal problem. Harat el al. [2] studied the economic and environmental aspects of the liquidation of coal mines. Jewartowski et al. [3] determined the optimal time of coal mine liquidation given the necessity of bearing the costs of post-mining reclamation. Batrancea et al. [4] carried out an econometric approach on production, costs, and profit in Romanian coal mining enterprises. Dvořáček et al. [5] developed research about the choice of the technical liquidation of underground mine workings. They analyzed the mining legislation in the mine liquidation processes in the Czech Republic. Janusz et al. [6] investigated the changes in hydrogeological conditions in the area of liquidated hard coal mines in the north-eastern part of Upper Silesia Coal Basin (Poland). They concluded that the groundwater inflow into the analyzed area was reduced by $43 \%$. The socioeconomic impacts of mine closure were analyzed by Rao and Pathak [7]. Other researchers also analyzed the mine liquidation processes and the socioeconomic impacts of mine closure [8-12]. Salom et al. [13] carried out a critical review of environmental impacts 
and constraints to rehabilitation in closed and abandoned mines in Namibia. Barabash et al. [14] analyzed the technical and economic aspects of the coal mine closure based on the geo-mechanical component assessment in Ukraine. The economic and financial aspects of mine closure were investigated by Kahn et al. [15]. Some research works about the optimization of mine closure processes and the impact of mine closure and its associated cost on life of mine planning were carried out [16-21].

In addition, some alternatives can be applied in closed mines to use the disused mining infrastructure. Underground pumped-storage hydropower (UPSH) plants can be built using the underground space as lower reservoir [22-25]. Menendez et al. [26] carried out a research work about closed mines in Spain as energy storage systems. In addition, abandoned mines can be also used as subsurface reservoirs of compressed air energy storage (CAES) systems [27-29]. The ambient air would be stored at high pressures in the drifts. In the Polish hard coal mining industry restructuring actions are realized. A rational reduction in costs of the mining industry may be based on the liquidation of mines that are considered as permanently unprofitable. The liquidation of the mine is regulated in the Polish legislation. According to the legislation on geology and mines, in the event of liquidation of the mining plant, in a whole or in a part, the entrepreneur is obliged to:

- Secure or liquidate mining excavations and mining equipment, installations, and facilities.

- $\quad$ Secure the unused part of the mineral deposit.

- $\quad$ Secure the neighboring mineral deposits.

- $\quad$ Take the necessary measures to protect the excavations of neighboring mining plants.

- Take the necessary measures to protect the environment and reclaim the land after mining activities.

Since 2000, SRK S.A. mining company, as the legal successor to the previous mining exploitation, has been managing the assets of the restructured hard coal mines. Eight branches of SRK S.A. are involved in the liquidation and protection of mining excavations in liquidated coal mines. The branch of SRK S.A. called Central Mine Dewatering Plant is responsible for securing the neighboring mines by pumping water out of the liquidated mining plants. The supervision and management of post-industrial property in the liquidated mines is carried out by Branches of SRK S.A. called Hard Coal Mines in Total Liquidation and Housing Resource Administration.

During the mine's existence, we can distinguish the period of the mine construction and the period of the mining deposit; however, the natural and inseparable element is the liquidation of the mining plant. The lack of cost management support instruments may make it difficult to improve the efficiency of liquidation. Although the average cost of the mine liquidation is around EUR 150 million, the scientific research concerning the rationalization and efficiency improvement of liquidation processes is very scarce $[7,8]$.

In this paper, a statistical analysis of the liquidation processes in hard coal mines in Poland was carried out. The proposed evaluation method of the amount of estimated liquidation costs described is based on the analysis of the total liquidation cost according to the SRK experience. The presented research is a continuation of research on the tools that support the cost management of liquidation processes. The presented method of assessing the correctness of the estimation of liquidation costs may affect the effectiveness and efficiency of a mining enterprise that liquidates coal mines.

\section{Materials and Methods}

The process management system in SRK S.A. requires the modernization of the available tools for assessing the course of the liquidation processes and the proposal of new ones. An additional research aim is to identify research areas and problems related to the rationalization and effectiveness of the liquidation processes that require analysis and solutions. The aim was achieved in two stages (Table 1). The research plan was carried out on the basis of the analysis of the Updated Mining Plant Closure Programs for 17 examples 
of mine liquidation or their separate parts. The analysis refers to the period from 2015 to 2023.

Table 1. Research methods and the results of their use in particular stages of research.

\begin{tabular}{cll}
\hline $\begin{array}{c}\text { Research } \\
\text { Stage }\end{array}$ & Research Methods & \multicolumn{1}{c}{ Results of the Use of Research Methods } \\
\hline & -Analysis & -A statistical analysis of the cost liquidation process. \\
I & -Synthesis & -A modification of data form. \\
& -Direct interview & -An actualization of proposed evaluation method. \\
& -Direct interview & -A verification of reached results. \\
II & -Analysis & -A modification of the evaluation method of the course \\
& -Synthesis & of liquidation processes.
\end{tabular}

In the first stage, the mine liquidation costs were analyzed and compared to the experience of SRK S.A. in the liquidation of coal mines in Poland. Moreover, the documentation concerning the conducted and ongoing restructuring processes in liquidated mines was analyzed. The results of the analysis made it possible to propose a method to optimize the cost management of the liquidation processes. During this stage, a direct interview was conducted with experts, concerning the technical problems of the liquidation processes, their correctness, and suggestions for possible changes in the liquidation practice. Interviews with people who manage the liquidation of analyzed branches dispelled the most important doubts and explained most of the cases of deviations from the established procedures. On this basis, it can be concluded that the performed liquidation process is correct and compliant with the 'mining and construction art' and that the activities that has been undertaken so far may constitute the basis for the development of the method for assessing the correctness of cost estimation of mine liquidation processes. The updated method was used in the second stage of the research.

In the second stage, basic statistical analysis of the liquidation processes in SRK S.A. was carried out. The encountered problems were explained with experts. The correct operation of the proposed liquidation process assessment tool was carried out in two stages. In the first stage, the software's reaction to the assigned cases of hypothetical new branches of SRK S.A. was assessed. In the second stage, the same cases were also presented to experts in practice managing the liquidation of coal mines. The research identified areas and research problems that need to be solved.

The research was carried out on the basis of the updated mine closure programs containing data on the performed and currently conducted mine liquidation processes. The liquidation of coal mines is financially accounted for by 10 component processes (Figure 1). SRK S.A. mining company has been conducting the liquidation of coal mines since 2000 and according to the updated programs for the liquidation of coal mines, it should be completed by the end of 2023 [7,8]. The liquidation of the mine is carried out in accordance with several models depending on the scope of the liquidation and the target model of the restructured mining plant. SRK S.A. may carry out the liquidation of the complete mine or its ineffective part. Due to the target model, the liquidation is carried out with the pumping station so as to protect the neighboring active coal mines or as complete when protection of neighboring mines is not required (Figure 1). In practice, the difference between the models focuses on the first 3 processes. In Figure 1, processes 1, 2, and 3 marked in lighter colors relate to the complete liquidation of the mine, while their darker version reflects the course of the process when the pumping station is left. In the case of leaving the pumping station, the part of the shafts and underground workings are not liquidated. They are being transferred to the Central Mine Dewatering plant that will protect the neighboring mines and the land surface against water hazards. It has not been necessary to liquidate a marked part of the mine, leaving the pumping station so far, which means that SRK S.A. liquidates mines only in 3 variants. 


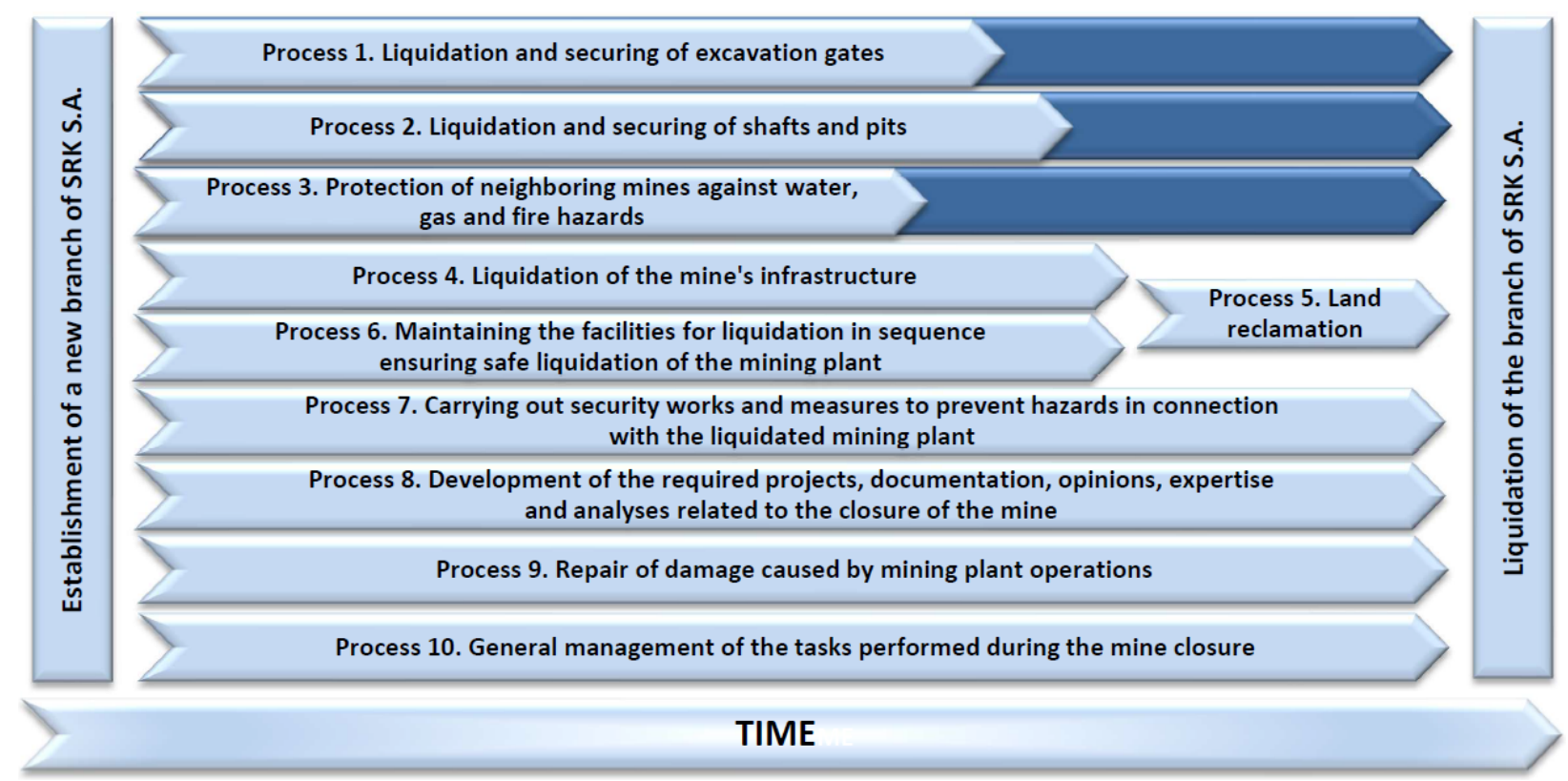

Figure 1. Mine liquidation processes in SRK S.A. Source: Data from SRK S.A.

\section{Results}

The publication presents a statistical analysis of six cases of completely liquidated coal mines. In order to increase the credibility of the research results, the mines that are currently liquidated and grouped administratively in eight branches of SRK S.A. were also subjected to the statistical analysis. To facilitate the analysis, these branches were divided into component mines. Thanks to that another group of 11 liquidation cases were obtained, which gives a total of 17 examples. In order not to disclose the sensitive data of SRK S.A., the liquidated mines were given working names in accordance with the decreasing cost of their liquidation, presented as a fraction expressed as a percentage of the total cost of liquidation of all 17 coal mines (Table 2). Inflation and changes in labor costs have resulted in incomparability of costs in different years; therefore, a proprietary correction coefficient developed on the basis of data from the Central Statistical Office was used. The liquidation cost converted into the realities of the first quarter of 2021 was analyzed.

Table 2. The costs of liquidated branches of SRK S.A. subjected to statistical analysis.

\begin{tabular}{cccccccccc}
\hline Branch & B1 & B2 & B3 & B4 & B5 & B6 & B7 & B8 & B9 \\
\hline & $16.16 \%$ & $12.75 \%$ & $10.27 \%$ & $9.98 \%$ & $8.94 \%$ & $6.93 \%$ & $6.19 \%$ & $5.88 \%$ & $5.43 \%$ \\
\hline \multirow{2}{*}{ Branch } & B10 & B11 & B12 & B13 & B14 & B15 & B16 & B17 & $0.32 \%$ \\
& $4.30 \%$ & $3.00 \%$ & $2.78 \%$ & $2.24 \%$ & $1.88 \%$ & $1.62 \%$ & $1.34 \%$ & \\
\hline
\end{tabular}

The liquidation of the mine is always a single case, which results in different costs (Figure 2). Figure 2 shows the numbers of subsequent liquidation processes on the horizontal axis, and the vertical axis shows the percentage of expenditures of individual branches for each of the processes. Cost differences result from the scale of the project. Higher liquidation costs depend on the number of maintained and liquidated facilities. The costs of other processes are in most cases a derivative of running the main processes $(1,2$, and 4$)$. This aspect of the liquidation cost structure requires deeper analysis and further research. 


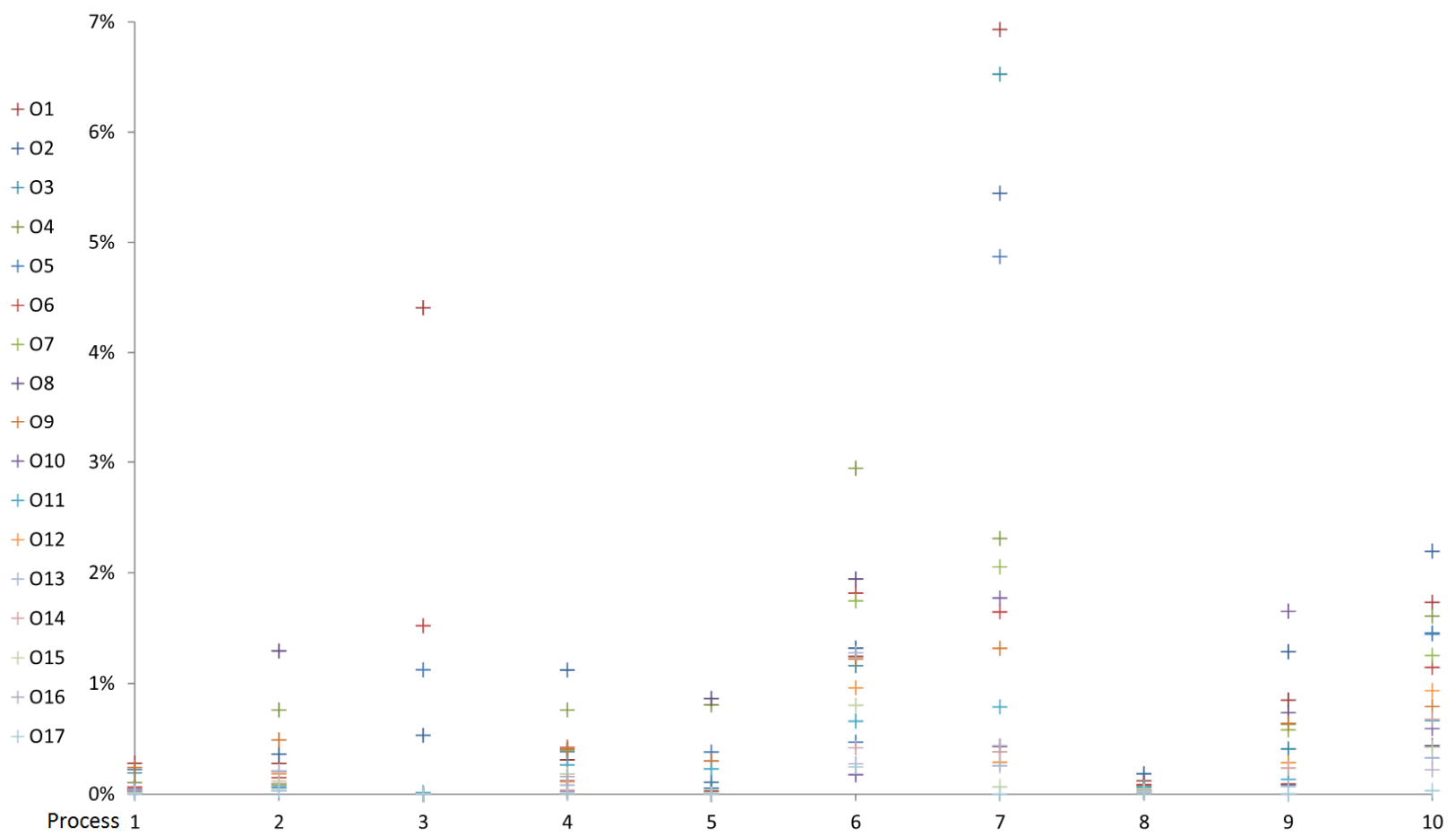

Figure 2. The distribution of the liquidation processes costs of branches of SRK S.A.

The state budget has allocated or will allocate more than EUR 1 billion to the liquidation of the analyzed branches, so even a small percentage reduction in the cost of liquidation means measurable financial benefits. Most of component processes of the liquidation of coal mines have potential for optimization and rationalization. The variation of the size of liquidation costs was analyzed using the compliance factor according to the Equation (1).

$$
V=\frac{s}{\bar{x}} \cdot 100
$$

where

$V$ is the compliance coefficient, $s$ is the standard deviation, and $\bar{x}$ is the arithmetic average. The standard deviation is estimation by applying Equation (2). $x_{i}$ is the successive characteristics of the population, $N$ is the number of observations in the population and $\mu$ is the expected value.

$$
\sigma=\sqrt{\frac{\sum_{i=1}^{N}\left(x_{i}-\mu\right)^{2}}{N}}
$$

If the coefficient of variation is in the range of $0-20 \%$, then the diversity of the population is small, when it is in the range of $20-40 \%$, it proves the average diversity of the population, and in the range of $40-60 \%$ it is highly differentiated. When the coefficient of variation exceeds $60 \%$, it means a great diversity of the population.

The coefficient of variation of components of costs of liquidation processes of the entire research group amounted to $119.41 \%$, which proves a very high variability of results. It has been found that this indicator is not reliable. Underground coal mines are liquidated according to three liquidation models, and this causes costs replacement in various component liquidation processes. Increasing the outlays in one process may reduce the capital intensity of another. For this reason, a better indicator of the differentiation of analyzed examples of liquidation is the analysis of the coefficient of differentiation of the total expenditures on the branch liquidation (CV), which, for all liquidated branches, amounted to $75.92 \%$ (Table 3). 
Table 3. The analysis of the branches of SRK S.A. as a one group.

\begin{tabular}{|c|c|c|}
\hline & Branches Included in the Group. & All \\
\hline $\mathrm{CV}$ & The coefficient of variation of total liquidation costs & $75.92 \%$ \\
\hline MA & The coefficient of variation in multi-criteria analysis & $153.89 \%$ \\
\hline Average CV & $75.92 \% \quad$ Average CV and MA & $114.91 \%$ \\
\hline
\end{tabular}

In order to increase cost consistency, it was proposed to divide the liquidated mines according to their total liquidation costs. As shown in Table 4, the division into 4 groups of branches was proposed-Large Branches (LB), Medium Larger Branches (MLB), Medium Smaller Branches (MSB), and Small Branches (SB).

Table 4. The analysis of the branches of SRK S.A. as a one group.

\begin{tabular}{|c|c|c|c|c|}
\hline Branches & \multirow{2}{*}{$\begin{array}{c}\text { LB } \\
\text { (above 9\%) }\end{array}$} & \multirow{2}{*}{$\begin{array}{c}\text { MLB } \\
\text { (from } 6 \% \text { to } 9 \% \text { ) }\end{array}$} & \multirow{2}{*}{$\begin{array}{c}\text { MSB } \\
\text { (from 3\% to } 6 \% \text { ) }\end{array}$} & \multirow{2}{*}{$\begin{array}{c}\text { SB } \\
\text { (to } 3 \%)\end{array}$} \\
\hline Cost & & & & \\
\hline $\mathrm{CV}$ & $23.29 \%$ & $19.4 \%$ & $27.62 \%$ & $49.66 \%$ \\
\hline MA & $6.66 \%$ & $9.75 \%$ & $39.17 \%$ & $104.85 \%$ \\
\hline \multicolumn{2}{|c|}{ Average CV } & $29.67 \%$ & Average $\mathrm{CV}$ and MA & $35.05 \%$ \\
\hline
\end{tabular}

The proposed division significantly improved the coefficient of variability of the liquidation costs of branches in groups (Table 5). The average coefficient of variation was $29.67 \%$. In individual groups, the amount of liquidation costs was actually satisfactory, except from the group of Small Branches (SB), and therefore the sorting criteria ought to be changed again.

Table 5. Multi-criteria analysis of liquidation processes costs "costs minimization".

\begin{tabular}{ccccc}
\hline \multirow{2}{*}{ Branches } & $\begin{array}{c}\text { LB } \\
\text { (to 1.0) }\end{array}$ & $\begin{array}{c}\text { MLB } \\
\mathbf{( 1 . 0} \text { to } \mathbf{2 . 5})\end{array}$ & $\begin{array}{c}\text { MSB } \\
\mathbf{( 2 . 5} \text { to 4.0) }\end{array}$ & $\begin{array}{c}\text { SB } \\
\text { (above 4.0) }\end{array}$ \\
\hline CV & $55.2 \%$ & $28.90 \%$ & $47.06 \%$ & $89.83 \%$ \\
MA & $51.81 \%$ & $15.98 \%$ & $11.86 \%$ & $32.55 \%$ \\
\hline \multicolumn{2}{c}{ Average CV } & $55.25 \%$ & Average CV and MA & $41.65 \%$ \\
\hline
\end{tabular}

In the next stage of the research, the branches were sorted according to the indicator obtained in the multi-criteria analysis of the costs of the components of the liquidation processes. This indicator shows the distance of the analyzed branch from the hypothetical branch with the most optimal parameters from the examined group of 17 branches. In the applied transformation, the analyzed parameters should be classified into groups according to their nature. In this method, the analyzed parameters were divided into "stimulant" - the increase in value of which is perceived positively, "destimulant" - the increase in value of which is perceived negatively, and "nominant" - the increase in value is perceived positively or negatively. In the examined example, all tested parameters are costs for which the increase is perceived negatively; therefore, the costs are assigned as the character of the "destimulant". In the multi-criteria analysis, each of the examined parameters is assigned as the weight that influences the overall result. In this case, it was assumed that each of the examined costs is equally significant and all costs were given a factor of one. Moreover, it was also found that further research will require assigning an appropriate weight to each of the costs. However, this will not affect the principle of operation of the method of the estimation of mining plant liquidation costs.

The applied transformation quotient method eliminates the problem of possible difference between the units of the analyzed parameters and the absolute size of the numbers describing individual parameters by locating the obtained values of individual 
parameters as a dimensionless number in the range from 0 to 1 . The value of the liquidation cost of a branch in the multi-criteria analysis for all the "destimulant" features, and assuming that the weights for all costs are equal to one, can be calculated according to the Equation (3):

$$
F C_{j \min }=\sum_{i=1}^{10} \frac{h_{i \min }}{h_{i j}}
$$

where $F C_{j \text { min }}$ is the liquidation cost of the branch " $j$ " in a multi-criteria approach, $i$ is the number of the mine liquidation component process, $j$ is the number of analyzed branch, $h_{i \min }$ the lowest cost value in the process " $i$ ", and $h_{i j}$ is the liquidation cost in the process " $i$ " for the branch " $j$ ".

Sorting branches according to the multi-criteria "cost minimization" gave much worse results than the previous sorting according to the amount of the total liquidation cost. The average coefficient of cost variation was as high as 55.25\% (Table 5).

For checking purposes, calculations were made where the costs were treated as "stimulants" and the branches were sorted according to the "cost maximization". This method of sorting revealed the optimal variant of grouping branches. When all parameters are "stimulants" and assuming that the weights for all costs are equal to one, the multicriteria evaluation using the quotient transformation is (4):

$$
F C_{j \max }=\sum_{i=1}^{10} \frac{h_{i j}}{h_{i \max }}
$$

where $F C_{j \max }$ is the liquidation cost of the branch " $j$ " in a multi-criteria approach, $i$ is the number of the mine liquidation component process, $j$ is the number of analyzed branch, $h_{i \text { max }}$ the highest cost value in the process " $i$ ", and $h i j$ is the liquidation cost in the process " $i$ " for the branch " $j$ ".

In the proposed division into four groups (Table 6), the average coefficient of variation is $28.89 \%$ and only the group of Small Branches differs significantly from the other groups. It was found that B17 differs from the rest of the group of Small Branches (SB) by more than three times of the amount of standard deviation. Because of that fact a Micro Branch (Micro B) was created as an additional fifth group that includes only one branch. After the exclusion of Branch 17 from the group of Small Branches (SB), the average coefficient of variability of the costs of the liquidation of branches in the analyzed groups decreased to $21.99 \%$. On the basis of the conducted analysis, it was found that when selecting the method of sorting branches, the average coefficient of variation of total costs and the average coefficient of variation of the multi-criteria value of costs, calculated as the average value of these values, should be taken into account. This allows for the combination of optimization of costs and the structure of these costs. The calculated average variation index for the previous divisions confirmed that the optimal variant of the division is the division into five groups in accordance with the "cost maximization" (Table 7).

Table 6. Multi-criteria analysis of liquidation processes costs "costs maximization".

\begin{tabular}{ccccc}
\hline \multirow{2}{*}{ Branches } & $\begin{array}{c}\text { LB } \\
\text { (above 4.0) }\end{array}$ & $\begin{array}{c}\text { MLB } \\
\mathbf{( 1 . 2 5} \text { to 4.0) }\end{array}$ & $\begin{array}{c}\text { MSB } \\
\mathbf{( 1 . 2 5} \text { to2.5) }\end{array}$ & $\begin{array}{c}\text { SB } \\
\text { (to 1.25) }\end{array}$ \\
\hline \multirow{2}{*}{ CV } & $21.43 \%$ & $22.15 \%$ & $22.62 \%$ & $49.35 \%$ \\
MA & $1.41 \%$ & $13.38 \%$ & $19.16 \%$ & $100.96 \%$ \\
\multicolumn{2}{c}{ Average CV } & $28.89 \%$ & Average CV and MA & $32.07 \%$ \\
\hline
\end{tabular}


Table 7. Multi-criteria analysis "costs maximization" (5 groups).

\begin{tabular}{|c|c|c|c|c|c|}
\hline Branches & $\begin{array}{c}\text { LB } \\
\text { (above 4.0) }\end{array}$ & $\begin{array}{c}\text { MLB } \\
(1.25 \text { to } 4.0)\end{array}$ & $\begin{array}{c}\text { MSB } \\
(1.25 \text { to } 2.5)\end{array}$ & $\begin{array}{c}\text { SB } \\
\text { (0.6 to } 1.25)\end{array}$ & $\begin{array}{c}\text { Micro B } \\
\text { (to 0.6) }\end{array}$ \\
\hline $\mathrm{CV}$ & $21.43 \%$ & $22.15 \%$ & $22.62 \%$ & $21.75 \%$ & \\
\hline MA & $1.41 \%$ & $13.38 \%$ & $19.16 \%$ & $14.07 \%$ & \\
\hline \multicolumn{2}{|c|}{ Average CV } & $21.99 \%$ & \multicolumn{2}{|c|}{ Average CV and MA } & $17.76 \%$ \\
\hline
\end{tabular}

On the basis of the obtained division into reference groups of values, a tool for the assessment of the amount of mine liquidation expenditures was proposed. The method signals deviations in the amount of costs for the total cost and the cost division into individual component processes. Figure 3 presents the idea of the assessment method against the entire population of analyzed liquidation examples. Most of the costs are outside the zone of acceptable values (white field between the green and red lines), and therefore the division into reference groups was made. The range of acceptable values results from the coefficient of variation established by the user, for which the standard deviation is calculated. The lower limit (green line) is determined by the mean value decreased by the calculated standard deviation, and the upper limit (red line) is determined by the mean value increased by the same value (Figure 3). So as to illustrate the method, it was assumed that the acceptable deviation would result from the adopted variability index equal to $20 \%$. This is the upper limit for a high match population.

$+\mathrm{B} 1$

$+\mathrm{B} 2$

$+\mathrm{B} 3$

$+\mathrm{B} 4$

$+\mathrm{B} 5$

$+\mathrm{B} 6$

$+\quad B 7$

$+\mathrm{B} 8$

B9

B10

B11

B12

B13

B14

B15

B16

B17

Medium

Upper limit

Lower limit

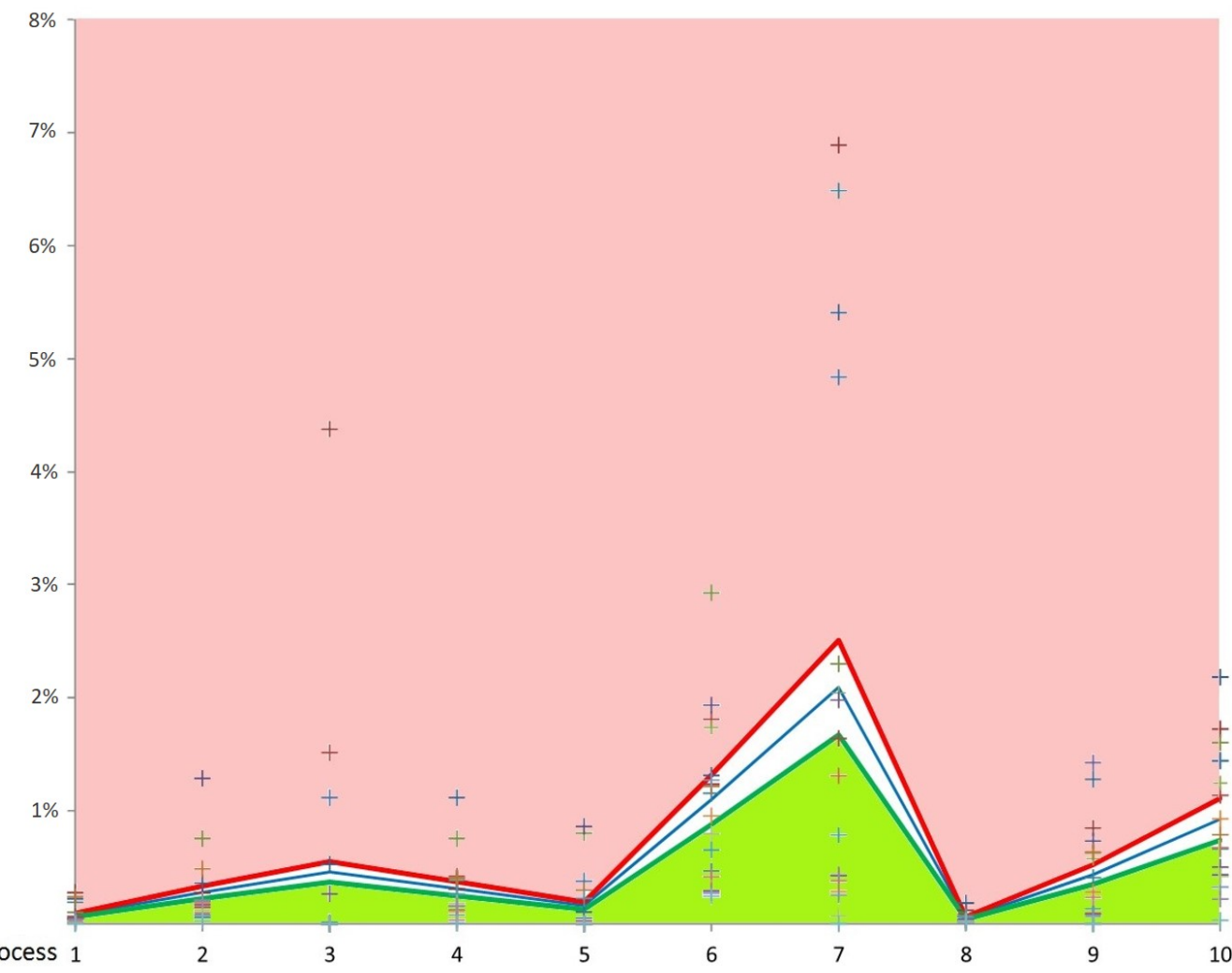

Figure 3. The idea of the assessment method of the correctness of the cost-estimation of mine liquidation processes.

\section{Discussion}

In the proposed method, the potential user enters the estimated liquidation costs for individual liquidation processes (fields marked as bright green in Figure 4) and enters the value of the coefficient of variation for each of the processes and for the total liquidation cost (fields marked pink). The software immediately informs in which reference group the analyzed case is. The blue field displays the name of the reference group (Figure 4). In this 
column, the obtained costs are compared to the average for each process and for the total liquidation cost in this reference group. When the entered cost exceeds the upper limit of the acceptable value, the field and digits turn into red. When the cost is below the lower limit of the acceptable value, the field and digits turn into green. Additionally, when the entered cost significantly (by more than three standard deviations) exceeds the lower or upper limit, the adjacent field turns into red. It was also proposed to signal the field in yellow, so as to take into account the fact of not incurring costs in a given process. The signaling of the deviation from the average value does not have to mean an error. Any deviation may result from the specificity of the liquidated branch and it is a place for the user's decision. For comparison, the costs entered by the user are analyzed in the same way for the entire population of the liquidated coal mines, which may additionally reassure the designer to the correctness of the estimated liquidation costs.

\begin{tabular}{|c|c|l|c|c|}
\hline $\begin{array}{c}\text { INSERT } \\
\text { Compl. Coeff. }\end{array}$ & $\begin{array}{c}\text { INSERT } \\
\text { Cost }\end{array}$ & \multicolumn{1}{|c|}{$\begin{array}{c}\text { EVALUATE IN GROUP } \\
\text { Processes }\end{array}$} & ALL & Mikro Branches \\
\hline $20 \%$ & & Process 1 (liquidation of excavations) & 0.000 & 0.000 \\
$20 \%$ & & Process 2 (liquidation of shafts and pits) & 0.000 & 0.000 \\
$20 \%$ & Process 3 (securing of neighbouring mines) & 0.000 & 0.000 \\
$20 \%$ & & Process 4 (liquidation of area facilities) & 0.000 & 0.000 \\
$20 \%$ & Process 5 (land reclamation) & 0.000 & 0.000 \\
$20 \%$ & Process 6 (maintenance of facilities above) & 0.000 & 0.000 \\
$20 \%$ & Process 7 (securing of liquidated mine) & 0.000 & 0.000 \\
$20 \%$ & Process 8 (projects, expertise, etc) & 0.000 & 0.000 \\
$20 \%$ & & Process 9 (mining damage) & 0.000 & 0.000 \\
$20 \%$ & & Process 10 (general management) & 0.000 & 0.000 \\
$20 \%$ & & Total & $\mathbf{0 . 0 0 0}$ & $\mathbf{0 . 0 0}$ \\
\hline
\end{tabular}

Figure 4. Screenshot of the liquidation costs assessment tool.

Currently, there are no actions that are going to provide negotiations so as to take over next branches to liquidate. Therefore, in order to verify the proposed method, a hypothetical takeover of four branches with working names: B18, B19, B20, and B21 was proposed. The first of the proposed branch is B18 with the value of component costs equal to twice of the liquidation costs of $\mathrm{B} 2$, with the highest cost in terms of multi-criteria attempt. The estimated cost of liquidation of B18 amounted to as much as $25.51 \%$ of the total costs incurred by SRK S.A. for the liquidation of analyzed 17 coal mines. B19 is another branch with the estimated amount of liquidation costs (1.64\% of the total cost) equal to the minimum values for the group of Medium Larger Branches (MLB). B20 is a branch with costs equal to the average costs for the group of Medium Smaller Branches (3.36\% of the total cost). The last of the hypothetical branches is B21 of which the liquidation costs were assumed as random values from the group of Medium Larger Branches (MLB), which amounted to $8.07 \%$ of the total cost.

As expected, B18 was analyzed in its upper part in the group of Large Branches (LB), in the case of four processes caused the signaling of exceeding the mean value, and in the comparison group, as many as six processes (Figure 5). Such reaction of the method was expected because the cost of liquidation of such a branch could be extremely high. In the case of process 3 (securing the neighboring mines) and process 5 (land reclamation), the software signaled an underestimation of expenses for the branch of this size. The prototype of the analyzed B18, branch B2 in this respect incurs extremely low expenditures. 


\begin{tabular}{|l|c|c|}
\hline \multicolumn{1}{|c|}{ EVALUATE IN GROUP } & All & Large Branches \\
\hline \multicolumn{1}{|c|}{ Processes } & $\%$ & $\%$ \\
\hline Process 1 (liquidation of excavations) & 0.004 & 0.004 \\
Process 2 (liquidation of shafts and pits) & 0.007 & 0.007 \\
Process 3 (securing of neighbouring mines) & 0.011 & 0.011 \\
Process 4 (liquidation of area facilities) & 0.022 & 0.022 \\
Process 5 (land reclamation) & 0.002 & 0.002 \\
Process 6 (maintenance of facilities above) & 0.026 & 0.026 \\
Process 7 (securing of liquidated mine) & 0.109 & 0.109 \\
Process 8 (projects, expertise, etc) & 0.004 & 0.004 \\
Process 9 (mining damage) & 0.026 & 0.026 \\
Process 10 (general management) & 0.044 & 0.044 \\
\hline Total & $\mathbf{0 . 2 5 5}$ & $\mathbf{0 . 2 5 5}$ \\
\hline
\end{tabular}

Figure 5. Assessment of the hypothetical branch B18 with twice value of the liquidation cost of branch B2.

The second of the analyzed branch is called B19. Despite the fact that the data was collected from the group of Medium Smaller Branches (MSB), it is qualified for the group of Small Branches (SB) in its central part (Figure 6). The method showed that processes 7 and 8 are below the average in this reference range, with the cost of process 8 only slightly above the upper limit of the limit. Process 2 showed a slight underestimation, while process 6 was well below the average. Figure 7 shows the analysis of the hypothetical branch B20 with average values of the liquidation costs of Medium Smaller Branches (MSB).

\begin{tabular}{|l|c|c|}
\hline \multicolumn{1}{|c|}{ EVALUATE IN GROUP } & All & Small Branches \\
\hline \multicolumn{1}{|c|}{ Processes } & $\%$ & $\%$ \\
\hline Process 1 (liquidation of excavations) & 0.000 & 0.000 \\
Process 2 (liquidation of shafts and pits) & 0.001 & 0.001 \\
Process 3 (securing of neighbouring mines) & 0.000 & 0.000 \\
Process 4 (liquidation of area facilities) & 0.001 & 0.001 \\
Process 5 (land reclamation) & 0.000 & 0.000 \\
Process 6 (maintenance of facilities above) & 0.005 & 0.005 \\
Process 7 (securing of liquidated mine) & 0.004 & 0.004 \\
Process 8 (projects, expertise, etc) & 0.000 & 0.000 \\
Process 9 (mining damage) & 0.001 & 0.001 \\
Process 10 (general management) & 0.004 & 0.004 \\
\hline Total & $\mathbf{0 . 0 1 6}$ & $\mathbf{0 . 0 1 6}$ \\
\hline
\end{tabular}

Figure 6. Assessment of the hypothetical branch B19 with minimal value of the liquidation cost of Medium Larger Branches (MLB).

\begin{tabular}{|l|c|c|}
\hline \multicolumn{1}{|c|}{ EVALUATE IN GROUP } & All & Medium Smaller \\
\hline \multicolumn{1}{|c|}{ Processes } & $\%$ & $\%$ \\
\hline Process 1 (liquidation of excavations) & 0.000 & 0.000 \\
Process 2 (liquidation of shafts and pits) & 0.001 & 0.001 \\
Process 3 (securing of neighbouring mines) & 0.000 & 0.000 \\
Process 4 (liquidation of area facilities) & 0.001 & 0.001 \\
Process 5 (land reclamation) & 0.001 & 0.001 \\
Process 6 (maintenance of facilities above) & 0.006 & 0.006 \\
Process 7 (securing of liquidated mine) & 0.009 & 0.009 \\
Process 8 (projects, expertise, etc) & 0.000 & 0.000 \\
Process 9 (mining damage) & 0.007 & 0.007 \\
Process 10 (general management) & 0.007 & 0.007 \\
\hline Total & $\mathbf{0 . 0 3 2}$ & $\mathbf{0 . 0 3 2}$ \\
\hline
\end{tabular}

Figure 7. Assessment of the hypothetical branch B20 with average values of the liquidation cost of Medium Smaller Branches (MSB). 
The analysis of costs of B20 also resulted in the expected reaction of the method. In this case, all the fields of liquidation components costs remained unresponsive to the method (Table 6), which was a reaction to the analysis of the reference example.

The biggest challenge for the methodology of assessment of liquidation costs was the analysis of the last case of B21 (Table 7), which was characterized by costs randomly selected from the group of Medium Larger Branches (MLB). This branch was situated in the upper zone of its reference group. The difficulty in assessing such a "creation" results from a very unbalanced cost structure. Some of them come from the group of more capital-intensive branches, and some from much less, so the amount of costs incurred and the arrangement of the colors of the fields in different colors may be a bit confusing for a practitioner dealing with the liquidation of mines. Figure 8 indicates the assessment of the hypothetical branch B21 with random values of the liquidation costs of Medium Larger Branches (MLB).

\begin{tabular}{|l|c|c|}
\hline \multicolumn{1}{|c|}{ EVALUATE IN GROUP } & All & Medium Larger \\
\hline \multicolumn{1}{|c|}{ Processes } & $\%$ & $\%$ \\
\hline Process 1 (liquidation of excavations) & 0.000 & 0.000 \\
Process 2 (liquidation of shafts and pits) & 0.001 & 0.001 \\
Process 3 (securing of neighbouring mines) & 0.011 & 0.011 \\
Process 4 (liquidation of area facilities) & 0.008 & 0.008 \\
Process 5 (land reclamation) & 0.004 & 0.004 \\
Process 6 (maintenance of facilities above) & 0.018 & 0.018 \\
Process 7 (securing of liquidated mine) & 0.021 & 0.021 \\
Process 8 (projects, expertise, etc) & 0.001 & 0.001 \\
Process 9 (mining damage) & 0.001 & 0.001 \\
Process 10 (general management) & 0.016 & 0.016 \\
\hline Total & $\mathbf{0 . 0 8 1}$ & $\mathbf{0 . 0 8 1}$ \\
\hline
\end{tabular}

Figure 8. Assessment of the hypothetical branch B21 with random values of the liquidation cost of Medium Larger Branches (MLB).

In this case, the method procedure worked properly and the signaling of deviations from the mean value is in line with the experts' opinion. In the second stage of the tool verification, the evaluation of the same variants by practitioners was convergent and the method of response was accepted.

\section{Conclusions}

Coal mine closure processes are being carried out in the European Union due to the current energy transition. A new economic tool has been developed to analyze the coal mine liquidation costs. The proposed method of the assessment of estimated cost of the mine liquidation can be used as a reference point for detailed analysis and multi-criteria cost planning. The system of accounting for the costs of liquidation component processes is typical for SRK S.A. In addition, with some modifications the proposed methodology can also be applied by another entity dealing with liquidation. The presented cost assessment procedure may facilitate the monitoring of conducted activities in terms of rationalization and minimization of the costs incurred. The proposed tool may be one of the components introducing the process approach in the field of effective liquidation of coal mines, which is particularly important in a situation where the scientific literature in this area is extremely scarce.

In order to protect the sensitive data at work, the actual costs incurred have been converted into a fraction of the total costs of liquidation. A similar analysis was carried out for the value expressed in money and converted to the total cost of the process, as well as to the maximum cost of liquidation of the branch. Due to the volume of the work, these results have not been included. The same results were obtained in all cases, which may prove the correctness of the proposed method. 
Finally, the proposed method for assessing the cost of mine liquidation is understandable, simple, and easy to use for applications in preliminary design works and ongoing engineering works.

Author Contributions: Conceptualization, J.S., A.C., M.G., J.M. and A.B.-S.; methodology, J.S., A.C., M.G., J.M. and A.B.-S.; software, J.S., A.C., M.G. and J.L.; investigation, J.S., A.C., M.G., J.M. and M.T.; validation, J.S., A.C. and M.G.; writing—original draft preparation J.S., A.C. and M.G.; writingreview and editing, J.M., J.L., M.T. and A.B.-S.; supervision, J.L and A.B.-S.; All authors have read and agreed to the published version of the manuscript.

Funding: This research received no external funding.

Institutional Review Board Statement: Not applicable.

Informed Consent Statement: Not applicable.

Data Availability Statement: Not applicable.

Conflicts of Interest: The authors declare no conflict of interest.

\section{References}

1. Grmela, A.; Harat, A.; Adamczyk, Z. The process of mines liquidation as an environmental, economic and legal problem. Ecol. Eng. Environ. Technol. 2017, 18, 39-45. [CrossRef]

2. Harat, A.; Adamczyk, Z.; Klupa, A. Economic and environmental aspects of the liquidation of coal mines. In Proceedings of the 17th International Multidisciplinary Scientific GeoConference SGEM 2017, Albena, Bulgaria, 29 June-5 July 2017; pp. 267-274.

3. Jewartowski, T.; Mizerka, J.; Mróz, C. Coal-mine liquidation as a strategic managerial decision: A decision-making model based on the options approach. Arch. Min. Sci. 2015, 60, 697-713.

4. Batrancea, I.; Batrancea, L.; Nichita, A.; Gaban, L.; Masca, E.; Morar, I.; Fatacean, G.; Moscviciov, A. An econometric approach on production, costs and profit in Romanian coal mining enterprises. Econ. Res. 2019, 32, 1019-1036. [CrossRef]

5. Dvořáček, J.; Štěrba, J. The Choice of the Technical Liquidation of Underground Mine Workings. In Proceedings of the First In-ternational Seminar on Mine Closure, Australian Centre for Geomechanics, Perth, Australia, 13-15 September 2006; pp. 257-260. [CrossRef]

6. Janusz, K.; Ewa, J.; Antoni, C. Changes of hydrogeological conditions in the area of liquidated hard coal mines in the north-eastern part of Upper Silesia Coal Basin (Southern Poland). In Proceedings of the 9th International Mine Water Congress, Oviedo, Spain, 5-7 September 2005; pp. 209-215.

7. Rao, M.; Pathak, K. Socioeconomic impacts of mine closure: A case study using satellite imagery. Int. J. Environ. Stud. 2005, 62, 555-570. [CrossRef]

8. Korski, J.; Korski, W. Underground mine as a system of processes. Min. Inform. Autom. Electr. Eng. 2015, 2, 19-27.

9. Mhlongo, S.; Amponsah-Dacosta, F. A review of problems and solutions of abandoned mines in South Africa. Int. J. Min. Reclam. Environ. 2016, 30, 279-294. [CrossRef]

10. Min, S.; Hyun-Koo, M.; Yangkyun, K.; Seung-Ah, L. A study on the subsidence risk evaluation using 3-D rock mass collapse simulation for abandoned mines. Geosystem Eng. 2017, 20, 51-58.

11. Mitchell, A.; Mackasey, W.O. A systematic inventory of abandoned mines-A powerful tool for risk management. Int. J. Surf. Min. Reclam. Environ. 1997, 11, 83-90. [CrossRef]

12. Smith, F.W.; Underwood, B. Mine closure: The environmental challenge. Min. Technol. 2000, 109, 202-209. [CrossRef]

13. Salom, A.T.; Kivinen, S. Closed and abandoned mines in Namibia: A critical review of environmental impacts and constraints to rehabilitation. S. Afr. Geogr. J. 2020, 102, 389-405. [CrossRef]

14. Barabash, M.; Salieiev, I.; Symanovych, H. Technical and technological aspects of the coal mine closure based on the geomechanical component assessment. Min. Miner. Depos. 2021, 15, 7-15. [CrossRef]

15. Kahn, J.; Franceschi, D.; Curi, A.; Vale, E. Economic and financial aspects of mine closure. Nat. Resour. Forum 2001, 25, 265-274. [CrossRef]

16. Nehring, M.; Cheng, X. An investigation into the impact of mine closure and its associated cost on life of mine planning and resource recovery. J. Clean. Prod. 2016, 127, 228-239. [CrossRef]

17. Laurence, D. Optimisation of the mine closure process. J. Clean. Prod. 2006, 14, 285-298. [CrossRef]

18. Bridge, G. Contested terrain: Mining and the environment. Annu. Rev. Environ. Resour. 2004, 29, 205-259. [CrossRef]

19. Amirshenava, S.; Osanloo, M. Mine closure risk management: An integration of $3 \mathrm{D}$ risk model and MCDM techniques. J. Clean. Prod. 2018, 184, 389-401. [CrossRef]

20. James, A.; Steve, N.; Stobart, B. Mine closure planning e time for a holistic approach. Mag. S. Afr. Inst. Civ. Eng. 2005, 13, $20-21$.

21. Gorey, P.; McHenry, M.; Morrison-Saunders, A.; Mtegha, H.; Doepel, D. Critical elements in implementing fundamental change in public environmental policy: Western Australia's mine closure and rehabilitation securities reform. Australas. J. Environ. Manag. 2016, 23, 370-381. [CrossRef] 
22. Pujades, E.; Willems, T.; Bodeux, S.; Orban, P.; Dassargues, A. Underground Pumped Storage Hydroelectricity Using Abandoned Works (Deep Mines or Open Pits) and the Impact on Groundwater Flow. Hydrogeol. J. 2016, 24, 1531-1546. [CrossRef]

23. Menéndez, J.; Ordóñez, A.; Álvarez, R.; Loredo, J. Energy from Closed Mines: Underground Energy Storage and Geothermal Applications. Renew. Sustain. Energy Rev. 2019, 108, 498-512. [CrossRef]

24. Menéndez, J.; Schmidt, F.; Konietzky, H.; Fernández-Oro, J.M.; Galdo, M.; Loredo, J.; Díaz-Aguado, M.B. Stability Analysis of the Underground Infrastructure for Pumped Storage Hydropower Plants in Closed Coal Mines. Tunn. Undergr. Space Technol. 2019, 94, 103117. [CrossRef]

25. Menéndez, J.; Schmidt, F.; Konietzky, H.; Bernardo, A.; Loredo, J. Empirical Analysis and Geomechanical Modelling of an Underground Water Reservoir for Hydroelectric Power Plants. Appl. Sci. 2020, 10, 5853. [CrossRef]

26. Menéndez, J.; Loredo, J.; Galdo, M.; Fernández-Oro, J.M. Energy Storage in Underground Coal Mines in NW Spain: Assessment of an Underground Lower Water Reservoir and Preliminary Energy Balance. Renew. Energy 2019, 134, 1381-1391. [CrossRef]

27. Schmidt, F.; Menéndez, J.; Konietzky, H.; Pascual-Muñoz, P.; Castro, J.; Loredo, J.; Bernardo, A. Converting closed mines into giant batteries: Effects of cyclic loading on the geomechanical performance of underground compressed air energy storage systems. $J$. Energy Storage 2020, 32, 101882. [CrossRef]

28. Lutyński, M. An overview of potential benefits and limitations of Compressed Air Energy Storage in abandoned coal mines. IOP Conf. Ser. Mater. Sci. Eng. 2017, 268, 012006. [CrossRef]

29. Álvarez de Prado, L.; Menéndez, J.; Bernardo-Sánchez, A.; Galdo, M.; Loredo, J.; Fernández-Oro, J.M. Thermodynamic analysis of Compressed Air Energy Storage (CAES) reservoirs in abandoned mines using different sealing layers. Appl. Sci. 2021, 11, 2573. [CrossRef] 